\title{
Women's Choice of Positions during Labour: Return to the Past or a Modern Way to Give Birth? A Cohort Study in Italy
}

\author{
Salvatore Gizzo, ${ }^{1,2}$ Stefania Di Gangi, ${ }^{1}$ Marco Noventa, ${ }^{1}$ Veronica Bacile, ${ }^{1}$ \\ Alessandra Zambon, ${ }^{1}$ and Giovanni Battista Nardelli $^{1}$ \\ ${ }^{1}$ Department of Woman and Child Health, University of Padua, 3 Giustiniani Street, 35128 Padua, Italy \\ ${ }^{2}$ Dipartimento di Salute della Donna e del Bambino, U.O.C. di Ginecologia e Ostetricia, Via Giustiniani 3, 35128 Padova, Italy \\ Correspondence should be addressed to Stefania Di Gangi; stefaniadig@yahoo.it
}

Received 24 February 2014; Revised 3 April 2014; Accepted 29 April 2014; Published 15 May 2014

Academic Editor: Anna T. Grazul-Bilska

Copyright (C) 2014 Salvatore Gizzo et al. This is an open access article distributed under the Creative Commons Attribution License, which permits unrestricted use, distribution, and reproduction in any medium, provided the original work is properly cited.

\begin{abstract}
Background. Childbirth medicalization has reduced the parturient's opportunity to labour and deliver in a spontaneous position, constricting her to assume the recumbent one. The aim of the study was to compare recumbent and alternative positions in terms of labour process, type of delivery, neonatal wellbeing, and intrapartum fetal head rotation. Methods. We conducted an observational cohort study on women at pregnancy term. Primiparous women with physiological pregnancies and single cephalic fetuses were eligible for the study. We considered data about maternal-general characteristics, labour process, type of delivery, and neonatal wellbeing at birth. Patients were divided into two groups: Group-A if they spent more than $50 \%$ of labour in a recumbent position and Group-B when in alternative ones. Results. 225 women were recruited (69 in Group-A and 156 in Group-B). We found significant differences between the groups in terms of labour length, Numeric Rating Scale score and analgesia request rate, type of delivery, need of episiotomy, and fetal occiput rotation. No differences were found in terms of neonatal outcomes. Conclusion. Alternative maternal positioning may positively influence labour process reducing maternal pain, operative vaginal delivery, caesarean section, and episiotomy rate. Women should be encouraged to move and deliver in the most comfortable position.
\end{abstract}

\section{Introduction}

For a long time, positions during labour could be freely changed or modified according to parturient desires.

Unfortunately, in developed countries the hospital admission of labouring women leads obstetrical practice to restrain spontaneous and instinctive attitude and to focus strictly on intrapartum fetal wellbeing and maternal comorbidities $[1,2]$.

This way, the parturient receives fewer opportunities to labour and deliver in a preferred position, assuming the recumbent one as standard because of its easier monitoring of fetal wellbeing, administration of intravenous therapy, loco-regional anaesthesia, and performance of medical procedures, perineal support, and birth assistance $[2,3]$.

The effects of different maternal positions during labour on maternal-fetal and neonatal outcomes are rarely in agreement and available evidences in this field are often controversial and fragmentary $[1,4,5]$.
The vertical positions may benefit from "gravity effect" potentially able to reduce aortocaval compression, to make uterine contractions effective and to favour a better fetus alignment in the birth canal and to increase pelvic outlet diameters, reducing intrapartum maternal and neonatal complications [6-9].

Anyway counterparts evidences reported an increased haemorrhagic risk associated with upright positions [1, 1012] due to more perineal damage than uterine atony (often requiring medical and surgical procedures and potentially impairing future pregnancy planning and chances) [13-15].

Certainly, recumbent position makes it easier to palpate the mother's abdomen in order to monitor contractions, to perform vaginal examinations and invasive manoeuvres, to check the fetal head position, and to assess the fetal heart rate.

Conversely, because of increased risk of maternal abdominal blood vessels compression, less effectiveness of uterine contractions, less perineal muscle relaxation, high rate of 
analgesia request, and long labour length, recumbent position seems associated with more operative deliveries, severe pain $[1,3,16]$, abnormal fetal heart trace, and greater episiotomy rate $[1,10,11,17,18]$.

Last but not least, since intrapartum complications are frequently reported when fetal occiput is in posterior position (OP), some authors investigated if maternal labouring position may have a role in facilitating spontaneous rotation to occiput anterior position (OA) without conclusive evidences [19-21].

The aim of our study was to compare patients spending in a recumbent position more than $50 \%$ of labour to those assuming a preferred alternative position (vertical position) in terms of intrapartum, maternal/fetal, and neonatal outcomes. The second aim of the study was to establish if differences exist among two groups in terms of fetal head rotation rate from $\mathrm{OP}$ to $\mathrm{OA}$.

\section{Methods}

We conducted an observational cohort study on pregnant women admitted to the delivery room of University of Padua, Woman and Child Health Department, in the interval time between January 2013 and December 2013.

All the enrolled patients have been properly informed about the aim of the study and they consented to the usage of their data according to the Italian law (675/96).

We considered primiparous women with uncomplicated pregnancies and single fetuses in cephalic presentation before or at the onset of labour eligible for the study.

According to the defined criteria, labour onset was defined by regular uterine contractions and cervical dilatation of at least $2 \mathrm{~cm}$; the second labour stage was defined when a full dilatation of the cervix is attained [22].

We considered inclusion criteria to be as follows: age more than 18 years, BMI between 18 and $30 \mathrm{Kg} / \mathrm{m}^{2}$, assessment of occiput fetal position at the labour onset and confirmed by ultrasound [23], and information about intrapartum analgesia administration. We excluded all cases of vaginal delivery in a previous cesarean section, cephalic fetal presentation after manual rotation of the fetus from OP to OA, labour induction, and augmentation.

General data of parturients were collected in an electronic service at recovery. Data about intrapartum care were collected through Friedman labour partogram and midwifery records. One of the authors, supported by the midwifery (V.B.), collected data daily and reported them in an excel database.

For all women, data about maternal general characteristics (age, BMI, and gestational age), labour process (length of first and second stages of labour, fetal occiput position at the labour onset and at birth, mean value of Numeric Rating Scale (NRS) score detected during labour and before analgesia administration when required, and analgesia request rate), mode of delivery (spontaneous, operative vaginal delivery or emergent caesarean section (CS), need of episiotomy, and rate of perineal tears in cases of vaginal deliveries), and neonatal wellbeing at birth (Apgar score at 5th, and fetal $\mathrm{pH}$ value at birth) were recorded.

Patients were included in Group-A when they spent more than $50 \%$ of their labour in recumbent position (supine or lateral) and in Group-B when they preferred an alternative position (upright, squatting, sitting on the ball, or "on all fours" position).

All eligible patients received exclusively a midwifery intrapartum care, except for urgent CS or operative vaginal deliveries cases. All eligible patients assumed a spontaneous position without any medical or midwifery prescription. Regarding the analgesia, all women received epidural analgesia, when required, without the use of opioid.

Maternal positions were considered as follows.

(i) Recumbent position: the pregnant is lying on her back, above the bed at an angle up to 45 degrees, or on her side preferring that one on which the fetal back and the occiput are located. A pillow between the legs (extended or flexed) was allowed.

(ii) Upright position: the woman is in an upright position standing by herself or against to a support (bed, chair, or partner).

(iii) Squatting position: the patient crouches during contraction and then recuperates during relaxation.

(iv) Sitting position: the pregnant is sitting on a bed, on a chair, or on a ball.

(v) Position "on all fours": the pregnant is kneeling and bent forward in order to support her weight with arms.

The primary endpoint of the study was to collect possible differences between two groups in terms of labour process, type of delivery, and neonatal wellbeing.

The secondary endpoint was to establish if differences exist among two groups (Group-A versus Group-B) in terms of fetal head rotation rate from OP to OA and into Group-B which is the best alternative position.

Statistical analysis was performed using SPSS (Chicago, IL) software for Windows version 18. We performed the Kolmogorov-Smirnov to test normality of distribution. Continuous data have been tested with the $t$-test, and categorical variables have been tested with the $\chi^{2}$ test or Fisher's exact test when appropriate. Statistical significance was defined as $P<0.05$.

\section{Results}

In the considered interval time, 225 women were eligible for the study. Among them, 69 patients joined Group-A and 156 joined Group-B. In detail, Group-B patients assumed the upright position in $46.1 \%$ of the cases, the sitting position in $21.1 \%$ of the cases, the "on all fours" position in $16.2 \%$ of the cases, and a balloon-squatting position in $16.6 \%$ of the cases.

Mean age was $31.13 \pm 6.1$ years (ranging $18-44$ years), mean BMI was $23.59 \pm 3.5 \mathrm{Kg} / \mathrm{m}^{2}$ (ranging $18-30 \mathrm{Kg} / \mathrm{m}^{2}$ ), and mean gestational age was $39.2 \pm 1.2$ weeks (ranging $37-41$ 
TABLE 1: Comparison between the groups (Group-A versus Group-B) in terms of maternal, labour, and neonatal characteristics (KolmogorovSmirnov tests showed a normal distribution of continuous variables).

\begin{tabular}{|c|c|c|c|}
\hline \multicolumn{4}{|c|}{ Maternal, labour, and neonatal characteristics } \\
\hline Variables & $\begin{array}{l}\text { Groups } \\
\text { (number) }\end{array}$ & $\begin{array}{c}\text { Mean }( \pm \text { standard } \\
\text { deviation })\end{array}$ & $P$ value \\
\hline \multirow{3}{*}{ Maternal age (years) } & Group-A (69) & $31.83(5.55)$ & \multirow{3}{*}{ n.s. } \\
\hline & Group-B (156) & $30.83(6.36)$ & \\
\hline & Total (225) & $31.13(6.13)$ & \\
\hline \multirow{3}{*}{$\begin{array}{l}\text { Gestational age at } \\
\text { birth (weeks) }\end{array}$} & Group-A (69) & $39.70(1.40)$ & \multirow{3}{*}{ n.s. } \\
\hline & Group-B (156) & $39.02(1.01)$ & \\
\hline & Total (225) & $39.23(1.18)$ & \\
\hline \multirow{3}{*}{ BMI } & Group-A (69) & $24.26(3.53)$ & \multirow{3}{*}{ n.s. } \\
\hline & Group-B (156) & $23.29(3.57)$ & \\
\hline & Total (225) & $23.59(3.58)$ & \\
\hline \multirow{3}{*}{$\begin{array}{l}\text { Intralabour pain } \\
\text { (Numeric Rating } \\
\text { Scale score) }\end{array}$} & Group-A (69) & $7.1(1.6)$ & \multirow{3}{*}{$P<0.001$} \\
\hline & Group-B (156) & $3.7(1.2)$ & \\
\hline & Total (225) & $4.72(2.1)$ & \\
\hline \multirow{3}{*}{$\begin{array}{l}\text { First stage labour } \\
\text { length (minutes) }\end{array}$} & Group-A (69) & $336.1(161.1)$ & \multirow{3}{*}{$P<0.001$} \\
\hline & Group-B (156) & $192.1(125.8)$ & \\
\hline & Total (225) & $230.2(149.9)$ & \\
\hline \multirow{3}{*}{$\begin{array}{l}\text { Second stage labour } \\
\text { length (minutes) }\end{array}$} & Group-A (69) & $84.4(57.8)$ & \multirow{3}{*}{$P<0.001$} \\
\hline & Group-B (156) & $34.4(32.6)$ & \\
\hline & Total (225) & $47.1(45.9)$ & \\
\hline Variables & $\begin{array}{c}\text { Groups } \\
\text { (number) }\end{array}$ & $\begin{array}{c}\text { Number } \\
\text { (percentage) }\end{array}$ & $P$ value \\
\hline \multirow{3}{*}{ Analgesia request } & Group-A (69) & $24(34.8)$ & \multirow{3}{*}{$P<0.0001$} \\
\hline & Group-B (156) & $15(9.6 \%)$ & \\
\hline & Total (225) & $39(17.3)$ & \\
\hline \multirow{3}{*}{$\begin{array}{l}\text { Occiput posterior } \\
\text { position at labour } \\
\text { onset }\end{array}$} & Group-A (69) & $28(40.6)$ & \multirow{3}{*}{ n.s. } \\
\hline & Group-B (156) & $57(36.5)$ & \\
\hline & Total (225) & $85(37.8)$ & \\
\hline \multirow{3}{*}{$\begin{array}{l}\text { Persistent occiput } \\
\text { posterior position at } \\
\text { delivery (except } \\
\text { cesarean sections) }\end{array}$} & Group-A (51) & $11 / 28(39.6)$ & \multirow{3}{*}{$P<0.001$} \\
\hline & Group-B (147) & $16 / 57(28)$ & \\
\hline & Total (198) & $27 / 85(31.7)$ & \\
\hline \multirow{3}{*}{ Apgar 5th minute $<7$} & Group-A (69) & $0(0)$ & \multirow{3}{*}{ n.s. } \\
\hline & Group-B (156) & $0(0)$ & \\
\hline & Total (225) & $0(0)$ & \\
\hline \multirow{3}{*}{$\mathrm{pH}<7.2$ at birth } & Group-A (69) & $9(13)$ & \multirow{3}{*}{ n.s. } \\
\hline & Group-B (156) & $30(19.2)$ & \\
\hline & Total (225) & $39(17.3)$ & \\
\hline
\end{tabular}

weeks). Group-A and Group-B were homogenous for general maternal characteristics (Table 1).

Data about labour process, intrapartum pain and analgesia request, type of delivery, and neonatal outcome are detailed, reported in Table 1 and Figures 1-4.

Significant statistical differences were found in the length of both first and second labour stages (mean value of $336.1 \pm 161.1$ versus $192.1 \pm 125.8 ; 84.4 \pm$ 57.8 versus $34.4 \pm 32.6$ minutes, resp.; $P<0.001$ ) (Figures 1-2; between two groups (Group-A versus Group-B)).
Similarly, significant differences in terms of pain level with a mean NRS score of $7.1 \pm 1.6$ versus $3.7 \pm 1.2$ were, respectively, detected $(P<0.001)$. The two groups significantly differed for the analgesia request rate, respectively, with $34.8 \%$ versus $9.6 \%$ rate $(P<0.0001)$ (Figure 3$)$.

Regarding the mode of delivery, $47.8 \%$ of Group-A patients delivered by vaginal route, $26.1 \%$ required operative vaginal delivery, and $26.1 \%$ underwent CS.

Group-B patients delivered in $87.1 \%$ by vaginal route and required operative vaginal delivery in $7.1 \%$ and CS in $5.8 \%$ $(P<0.001)$ (Figure 4$)$. 


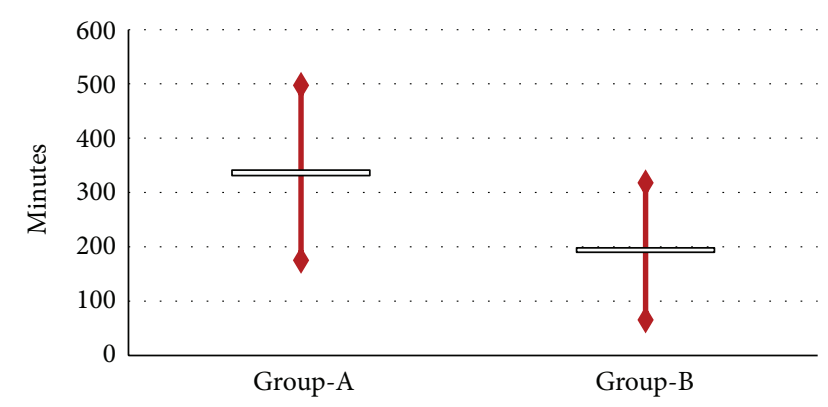

Group-A $(336.1 \pm 161.1)$

Group-B $(192.1 \pm 125.8)$

Figure 1: Comparison between the groups (Group-A versus GroupB) in terms of length of first stage of labour.

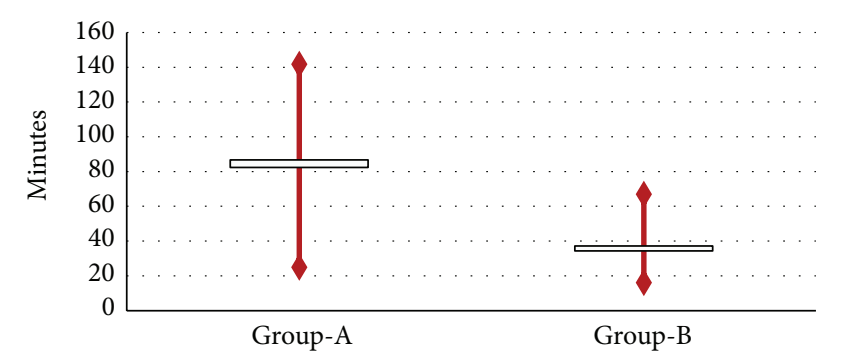

Group-A $(84.4 \pm 57.8)$

Group-B $(34.4 \pm 32.6)$

Figure 2: Comparison between the groups (Group-A versus GroupB) in terms of length of second stage of labour.

In Group-A, dystocia occurred in $13.05 \%$ of the cases and abnormal fetal heart rate in $13.05 \%$ of the cases while in Group-B this condition occurred, respectively, in $0.7 \%$ and $5.1 \%(P<0.05)$ (Figure 4).

Episiotomy was performed in 100\% of Group-A patients who delivered by vaginal route compared to the $32.7 \%$ of Group-B $(P<0.001)$, while 1st-2nd degree vaginal tears occurred, respectively, in $5.9 \%$ versus $49 \%$ of the cases $(P<0.001)$; no differences between two groups in terms of neonatal outcomes were reported.

Concerning the distribution of fetal occiput position at the labour onset, the OP rate resulted in being comparable in two groups with $40.6 \%$ in Group-A and 36.5\% in Group-B ( $P$ : n.s.).

Considering OP cases (28 cases in Group-A and 57 cases in Group-B) a strong significant difference was found in terms of delivery outcome.

CS was necessary in 27 patients: $46.4 \%$ in Group-A compared to the $12.3 \%$ in Group-B $(P<0.0001)$.

Significant differences in terms of OP persistence at delivery were also found in those delivering vaginally: in Group-A patients, OP persisted till birth in $39.6 \%$ of the cases while in Group-B only in $28 \%$ of the cases $(P<0.001)$.

Considering only Group-B patients, no differences were found comparing alternative position for all the outcomes considered. Detailed data are summarized in Table 1 and Figures 1-4.

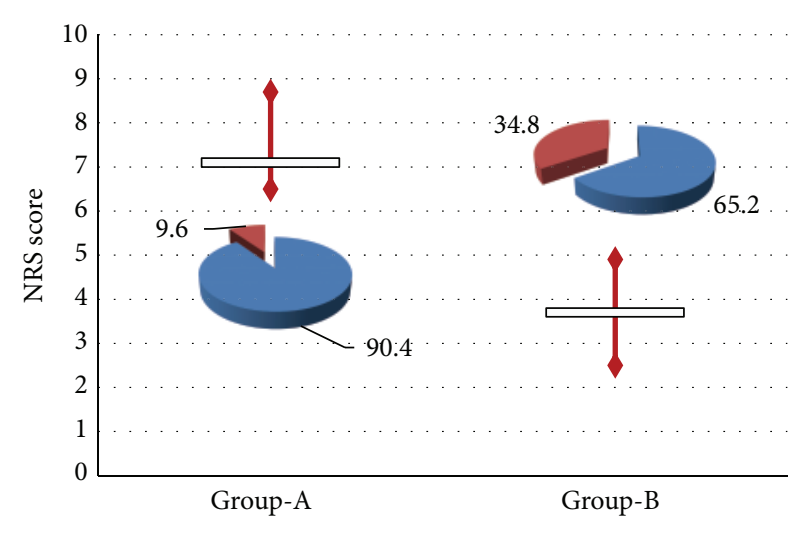

Group-A $(7.1 \pm 1.6)$

Group-B $(3.7 \pm 1.2)$

FIGURE 3: Comparison between the groups (Group-A versus GroupB) in terms of intrapartum NRS score and epidural analgesia request rate.

\section{Discussion}

A satisfying childbirth experience is influenced by women's self-control, labour pain perception, expectations, and health care support. The possibility to change the position in labour might positively influence childbirth experience and also the good course and outcome of labour [24].

Several advantages have been claimed for nonrecumbent labour, thanks to "gravity effect" on uterine perfusion, on contractions effectiveness, and on fetal alignment to the pelvic angles and diameters [18].

In the first stage of labour vertical positions seem associated with lower pain, reduced labour length, and perception of physiological event, resulting in an increased women's comfort and satisfaction after childbirth $[25,26]$.

These evidences have been confirmed in a recent metaanalysis revealing that vertical positions are also associated with a lower analgesia request and necessity of interventions [4].

However, all the existing studies did not provide a definitive message and were postponed to further investigation to define the real role of position in the labour process $[1,4,5]$.

Although some authors reported no effect of maternal position on labour length $[18,27,28]$ a significant reduction in length of both first and second labour stages was found in our patients assuming alternative positions and confirming a possible favouring effect of gravity in effective uterine contractions and fetal alignment to the birth canal. Episiotomy, operative vaginal delivery, and severe vaginal tears rate confirmed in our series of cases previous evidences regarding the positive effect of alternative position $[9,29-32]$.

This finding can be related to a better and gradual maternal perineum compliance to the fetal head descent, reducing anatomical and functional perineal damage and consequent dyssynergia.

Vertical positions are burned to more difficult medical management when peculiar conditions (amniotomy, oxytocin induction, fetal monitoring, and uterine contraction tracings) and interventions (epidural analgesia) are required 


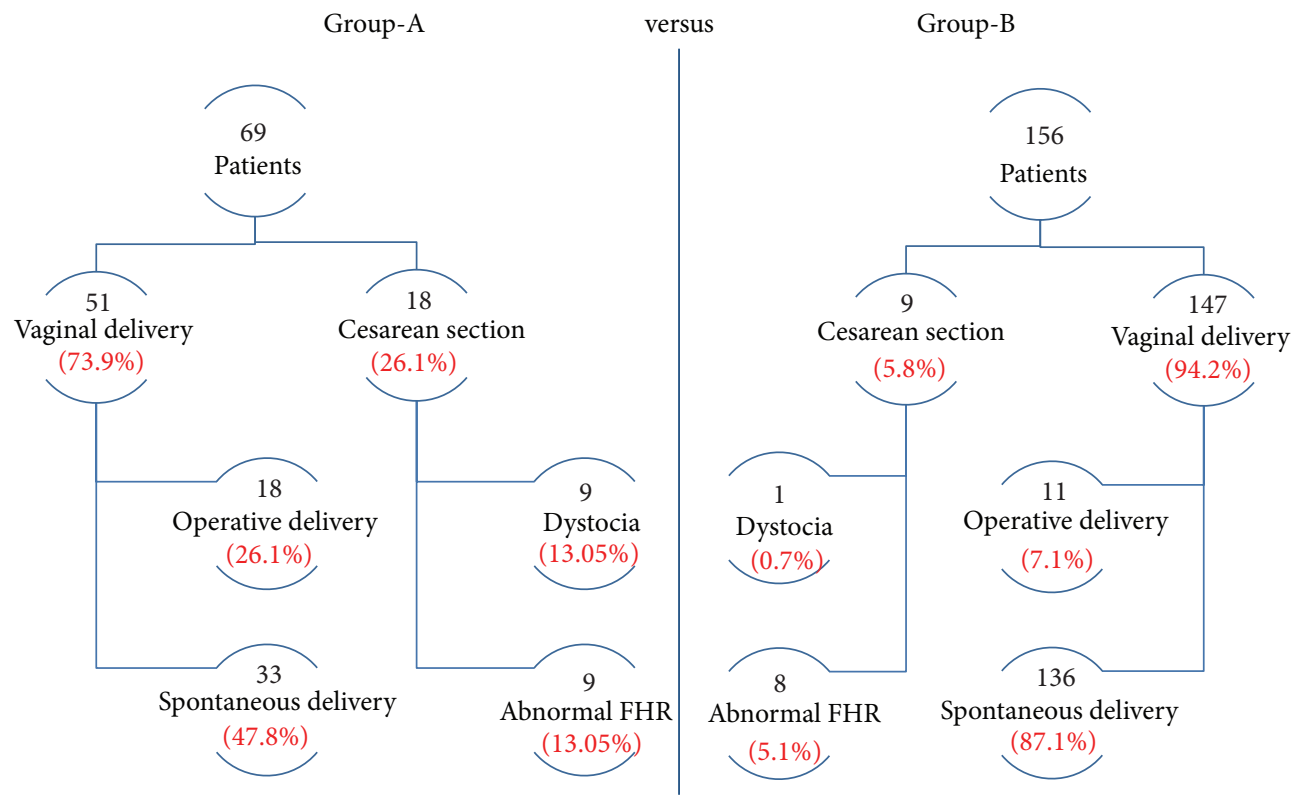

FIGURE 4: Flow diagram reporting type of delivery and indication of intrapartum caesarean section (comparison between the groups: Group-A versus Group-B).

and spontaneous movements and position change are not feasible [25].

Nevertheless, several studies reported that when a spontaneous analgesic and comfortable position is allowed, labouring women may benefit from a shorter labour length, avoidance of augmentation, and lower pain, reaching childbirth with strong motivation $[7,8,16,33]$. In agreement with previous studies, a significantly lower analgesia rate was recorded when a vertical position was assumed, compared to the recumbent one (probably due to lower perineum reflex muscle contraction of upright position).

If on one hand intrapartum epidural analgesia is considered a safe and effective procedure [34, 35], on the other hand it represents an adjunctive cause of maternal hypomobilization during labour and an indirect risk cofactor for fetal malposition persistence [19].

Many authors postulated that intrapartum persistent OP position (general prevalence ranging from $2 \%$ to $13 \%$ ) represents a risk factor for poor maternal and neonatal outcomes $[19,23,36]$.

When a persistent $O P$ occurs, different adverse obstetrical events are reported such as prolonged first and second labour stages, increased epidural analgesia request, higher risk of postpartum haemorrhage, increased CS, operative vaginal deliveries, and 3rd- and 4th-degree perineal tears rate $[19,23$, 36].

Frequently these intrapartum conditions resulted in low Apgar score, neonatal trauma, acidemic cord blood gas concentrations, admission to neonatal intensive care unit, and newborn encephalopathy $[19,23,36]$.

Different obstetrical manoeuvres have been proposed to facilitate the fetal head rotation from OP to OA (oxytocin augmentation and manual rotation), but none resulted in being more effective than maternal vertical position during labour $[19,20]$.

In a cohort of 225 parturients we found that vertical positions appeared helpful in foetal head rotation during labour, reducing the rate of operative vaginal deliveries and CS. Unfortunately, our sample did not allow us to discriminate which vertical position has to be preferred. Stremler et al. suggested that hands-and-knees positioning was more effective than others in reducing persistent back pain and favouring rotation of OP to OA but their study sample did not reach statistical power [37].

The upright position takes advantage of the gravity, increased size of the pelvic diameter, thanks to the nutation movement and to the coccyx retropulsion, the decline of the extreme cephalic, less painful and more effective contractions, pain relief for reduced pressure on the sacrum, increased confidence in the second labour stage, and lower perineum stretch. The sitting position takes advantage on gravity, on use of lumbar massage, and on an increased pelvic diameter with better fetal alignment to the pelvis, but it may increase the pressure on the sacrum with a major risk of perineal trauma. The "on all fours" position reduces the effect of gravity, the peak and duration of the contractions, and the pain due to a lower fetal pressure on the pelvis; it allows practicing the lumbar massage and favors the fetal internal rotation. This is the most recommended position to correct and prevent fetal malposition, to reduce cervical edema and the sacral pressure of the presenting part, and to increase the pelvic anteroposterior diameter in the expulsive phase. The squatting position allows using gravity, increasing the pelvic diameters and the counternutation for the fetal head descent, and strengthening the feeling of thrust and relaxation of perineal muscles $[25,38]$. 
Our encouraging results about vertical positions need to be further confirmed by large cohort studies and do not solve the existing debate.

Unfortunately, nowadays the "gravity effect" able to increase the maternal perineum compliance to fetal progression should be considered a theoretical assumption. Considering available literature and in absence of clear and strong evidences, it seems reasonable not to impose on women a labouring posture different from the spontaneous one [21].

Although Golara et al. [39] suggested that the maternal immobilization during labour may increase the incidence of dystocia, when strict monitoring of fetal wellbeing [40] and high risk pregnancy medicalization [41-44] or intensive intrapartum care are necessary, the use of alternative positions should be carefully evaluated.

Our data on a series of uncomplicated pregnancies allows us to suggest that, in absence of prelabour or intralabour complications, the alternative vertical positions may positively influence labour process reducing maternal pain and operative vaginal delivery, CS, and episiotomy rate.

Our study is actually the first one assessing the role of maternal labouring vertical position in occiput rotation from $\mathrm{OP}$ to OA demonstrating its real benefit on labour process and delivery.

Although further studies in this field are mandatory and most theoretical speculations need to be clarified, in absence of prepartum/intrapartum maternal-fetal complications, all women should be encouraged to move and to deliver in the most comfortable position, preferring a vertical position when OP is diagnosed.

\section{Conflict of Interests}

The authors declare that there is no conflict of interests regarding the publication of this paper.

\section{Acknowledgments}

The authors thank all the team of the Delivery Room of Unit of Gynaecology and Obstetrics Clinic of Padua.

\section{References}

[1] J. K. Gupta, G. J. Hofmeyr, and M. Shehmar, "Position in the second stage of labour for women without epidural anaesthesia," The Cochrane Database of Systematic Reviews, vol. 5, 2012.

[2] A. de Jonge, M. E. B. Rijnders, M. T. van Diem, P. L. H. Scheepers, and A. L. M. Lagro-Janssen, "Are there inequalities in choice of birthing position?. Sociodemographic and labour factors associated with the supine position during the second stage of labour," Midwifery, vol. 25, no. 4, pp. 439-448, 2009.

[3] L. Thies-Lagergren, I. Hildingsson, K. Christensson, and L. J. Kvist, "Who decides the position for birth? A follow-up study of a randomised controlled trial," Women and Birth, vol. 26, no. 4, pp. e99-e104, 2013.

[4] A. Lawrence, L. Lewis, G. J. Hofmeyr, T. Dowswell, and C. Styles, "Maternal positions and mobility during first stage labour," Cochrane Database of Systematic Reviews, vol. 15, no. 2, 2009.
[5] E. Kemp, C. J. Kingswood, M. Kibuka, and J. G. Thornton, "Position in the second stage of labour for women with epidural anaesthesia," Cochrane Database of Systematic Reviews, vol. 1, Article ID 008070, 2013.

[6] J. P. Souza, M. A. Miquelutti, J. G. Cecatti, and M. Y. Makuch, "Maternal position during the first stage of labor: a systematic review," Reproductive Health, vol. 3, article 10, 2006.

[7] S.-C. Chang, M.-M. Chou, K.-C. Lin, L.-C. Lin, Y.-L. Lin, and S.-C. Kuo, "Effects of a pushing intervention on pain, fatigue and birthing experiences among Taiwanese women during the second stage of labour," Midwifery, vol. 27, no. 6, pp. 825-831, 2011.

[8] L. B. Regaya, R. Fatnassi, A. Khlifi et al., "Role of deambulation during labour: a prospective randomized study," Journal de Gynecologie Obstetrique et Biologie de la Reproduction, vol. 39, no. 8, pp. 656-662, 2010.

[9] C. Walker, T. Rodríguez, A. Herranz, J. A. Espinosa, E. Sánchez, and M. Espuña-Pons, "Alternative model of birth to reduce the risk of assisted vaginal delivery and perineal trauma," International Urogynecology Journal, vol. 23, no. 9, pp. 12491256, 2012.

[10] A. De Jonge and A. L. M. Lagro-Janssen, "Birthing positions. A qualitative study into the views of women about various birthing positions," Journal of Psychosomatic Obstetrics and Gynecology, vol. 25, no. 1, pp. 47-55, 2004.

[11] A. De Jonge, T. A. M. Teunissen, and A. L. M. Lagro-Janssen, "Supine position compared to other positions during the second stage of labor: a meta-analytic review," Journal of Psychosomatic Obstetrics and Gynecology, vol. 25, no. 1, pp. 35-45, 2004.

[12] A. De Jonge, M. T. Van Diem, P. L. H. Scheepers, K. M. Van Der Pal-De Bruin, and A. Lagro-Janssen, "Increased blood loss in upright birthing positions originates from perineal damage," BJOG: An International Journal of Obstetrics and Gynaecology, vol. 114, no. 3, pp. 349-355, 2007.

[13] S. Gizzo, C. Saccardi, T. S. Patrelli et al., "Fertility rate and subsequent pregnancy outcomes after conservative surgical techniques in postpartum hemorrhage: 15 years of literature," Fertility and Sterility, vol. 99, no. 7, pp. 2097-2107, 2013.

[14] S. Gizzo, C. Saccardi, T. S. Patrelli, S. Di Gangi, D. D’Antona, and G. Battista Nardelli, "Bakri balloon in vaginal-perineal hematomas complicating vaginal delivery: a new therapeutic approach," Journal of Lower Genital Tract Disease, vol. 17, no. 2, pp. 125-128, 2013.

[15] S. Gizzo, T. S. Patrelli, S. D. Gangi et al., "Which uterotonic is better to prevent the postpartum hemorrhage? Latest news in terms of clinical efficacy, side effects, and contraindications: a systematic review," Reproductive Sciences, vol. 20, no. 9, pp. 10111019, 2013.

[16] E. Nilsen, H. Sabatino, and M. H. B. de MoraesLopes, “The pain and behavior of women during labor and the different Positions for childbirth," Revista da Escola de Enfermagem, vol. 45, no. 3, pp. 557-565, 2011.

[17] R. H. Shermer and D. A. Raines, "Positioning during the second stage of labor: moving back to basics," Journal of Obstetric, Gynecologic, \& Neonatal Nursing, vol. 26, no. 6, pp. 727-734, 1997.

[18] J. K. Gupta and C. Nikodem, "Maternal posture in labour," European Journal of Obstetrics Gynecology and Reproductive Biology, vol. 92, no. 2, pp. 273-277, 2000.

[19] P. Simkin, "The fetal occiput posterior position: State of the science and a new perspective," Birth, vol. 37, no. 1, pp. 61-71, 2010. 
[20] M.-J. Guittier and V. Othenin-Girard, "Correcting occiput posterior position during labor: the role of maternal positions," Gynecologie Obstetrique Fertilite, vol. 40, no. 4, pp. 255-260, 2012.

[21] R. Desbriere, J. Blanc, R. Le Dû et al., "Is maternal posturing during labor efficient in preventing persistent occiput posterior position? A randomized controlled trial," American Journal of Obstetrics \& Gynecology, vol. 208, no. 1, pp. e1-e8, 2013.

[22] F. G. Cunningham, K. J. Leveno, S. L. Bloom, J. C. Hauth, L. C. Gilstrap III, and K. D. Wenstrom, "Normal labor and delivery," in Williams Obstetrics, K. J. Leveno, Ed., pp. 409-441, McGrawHill, 22nd edition, 2005.

[23] S. Gizzo, C. Saccardi, S. Di Gangi et al., "Ultrasound investigation during labour of consensual or nonconsensual fetal spine in an occiput posterior cephalic presentation can improve the management of delivery?" Ultrasound in Medicine and Biology, vol. 39, no. 3, pp. 550-551, 2013.

[24] M. J. Nieuwenhuijze, A. de Jonge, I. Korstjens, L. Budé, and T. L. Lagro-Janssen, "Influence on birthing positions affects women's sense of control in second stage of labour," Midwifery, vol. 29, no. 11, pp. 107-114, 2013.

[25] E. Zwelling, "Overcoming the challenges: maternal movement and positioning to facilitate labor progress," MCN The American Journal of Maternal/Child Nursing, vol. 35, no. 2, pp. 72-78, 2010.

[26] S. Hunter, G. J. Hofmeyr, and R. Kulier, "Hands and knees posture in late pregnancy or labour for fetal malposition (lateral or posterior)," Cochrane database of systematic reviews, no. 4 , 2007.

[27] C. L. Roberts, C. S. Algert, C. A. Cameron, and S. Torvaldsen, "A meta-analysis of upright positions in the second stage to reduce instrumental deliveries in women with epidural analgesia," Acta Obstetricia et Gynecologica Scandinavica, vol. 84, no. 8, pp. 794798, 2005.

[28] M. A. Miquelutti, J. G. Cecatti, and M. Y. Makuch, "Upright position during the first stage of labor: a randomised controlled trial," Acta Obstetricia et Gynecologica Scandinavica, vol. 86, no. 5, pp. 553-558, 2007.

[29] P. Simkin, "Supportive care during labor: a guide for busy nurses," Journal of Obstetric, Gynecologic, and Neonatal Nursing, vol. 31, no. 6, pp. 721-732, 2002.

[30] I. Meyvis, B. Van Rompaey, K. Goormans et al., "Maternal position and other variables: effects on perineal outcomes in 557 births," Birth, vol. 39, no. 2, pp. 115-120, 2012.

[31] A. De Jonge, M. T. Van Diem, P. L. H. Scheepers, S. E. Buitendijk, and A. L. M. Lagro-Janssen, "Risk of perineal damage is not a reason to discourage a sitting birthing position: a secondary analysis," International Journal of Clinical Practice, vol. 64, no. 5, pp. 611-618, 2010.

[32] L. A. Smith, N. Price, V. Simonite, and E. E. Burns, "Incidence of and risk factors for perineal trauma: a prospective observational study," BMC Pregnancy and Childbirth, vol. 13, no. 59, 2013.

[33] L. Thies-Lagergren, L. J. Kvist, K. Christensson, and I. Hildingsson, "No reduction in instrumental vaginal births and no increased risk for adverse perineal outcome in nulliparous women giving birth on a birth seat: results of a Swedish randomized controlled trial," BMC Pregnancy and Childbirth, vol. 11, article 22, 2011.

[34] S. Gizzo, M. Noventa, S. Fagherazzi et al., "Update on best available options in obstetrics anaesthesia: perinatal outcomes, side effects and maternal satisfaction. Fifteen years systematic literature review," Archives of Gynecology and Obstetrics. In press.
[35] S. Gizzo, S. Di Gangi, C. Saccardi et al., "Epidural analgesia during labor: impact on delivery outcome, neonatal well-being, and early breastfeeding," Breastfeeding Medicine, vol. 7, no. 4, pp. 262-268, 2012.

[36] Y. W. Cheng, A. Hubbard, A. B. Caughey, and I. B. Tager, "The association between persistent fetal occiput posterior position and perinatal outcomes: an example of propensity score and covariate distance matching," American Journal of Epidemiology, vol. 171, no. 6, pp. 656-663, 2010.

[37] R. Stremler, E. Hodnett, P. Petryshen, B. Stevens, J. Weston, and A. R. Willan, "Randomized controlled trial of hands-and-knees positioning for occipitoposterior position in labor," Birth, vol. 32, no. 4, pp. 243-251, 2005.

[38] L. Hanson, "Second-stage labor care: challenges in spontaneous bearing down," Journal of Perinatal and Neonatal Nursing, vol. 23, no. 1, pp. 31-39, 2009.

[39] M. Golara, F. Plaat, and A. H. Shennan, "Upright versus recumbent position in the second stage of labour in women with combined spinal-epidural analgesia," International Journal of Obstetric Anesthesia, vol. 11, no. 1, pp. 19-22, 2002.

[40] T. S. Patrelli, F. D’Addetta, S. Gizzo et al., "Correlation between fetal movement revealed in actography and fetal-neonatal wellbeing: observational study on 3,805 pregnancies followed in a Northern Italy tertiary care hospital," Clinical and experimental obstetrics \& gynecology, vol. 38, no. 4, pp. 382-385, 2011.

[41] R. Berretta, S. Gizzo, A. Dall'Asta et al., "Risk of preterm delivery associated with prior treatment of cervical precancerous lesion according to the depth of the cone," Disease Markers, vol. 35, no. 6, pp. 721-726, 2013.

[42] S. Gizzo, T. S. Patrelli, M. Rossanese et al., "An update on diabetic women obstetrical outcomes linked to preconception and pregnancy glycemic profile: a systematic literature review," Scientific World Journal, vol. 2013, Article ID 254901, 9 pages, 2013.

[43] T. S. Patrelli, S. Gizzo, E. Cosmi et al., "Maternal hydration therapy improves the quantity of amniotic fluid and the pregnancy outcome in third-trimester isolated oligohydramnios: a controlled randomized institutional trial," Journal of Ultrasound in Medicine, vol. 31, no. 2, pp. 239-244, 2012.

[44] V. Zanardo, T. Fanelli, G. Weiner et al., "Intrauterine growth restriction is associated with persistent aortic wall thickening and glomerular proteinuria during infancy," Kidney International, vol. 80, no. 1, pp. 119-123, 2011. 


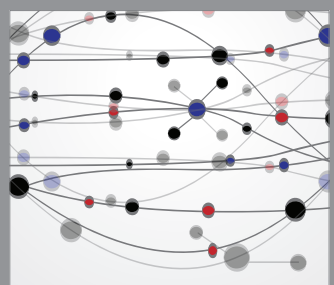

The Scientific World Journal
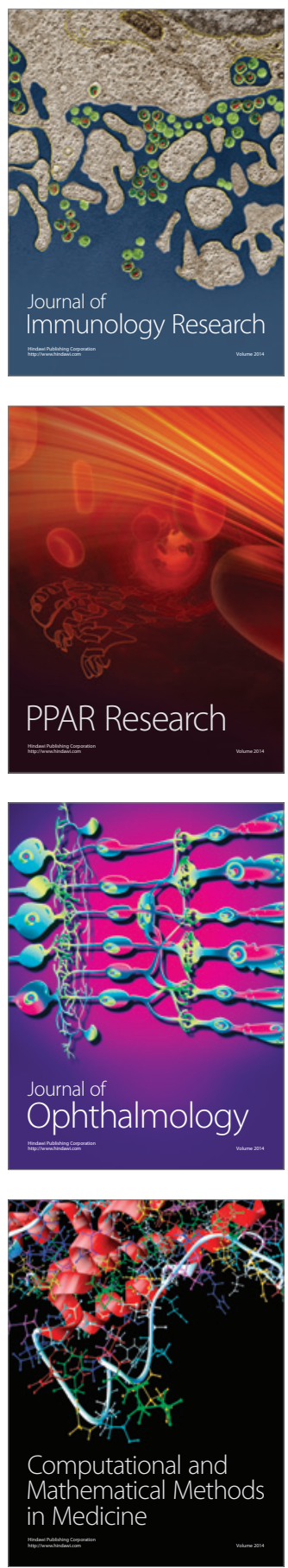

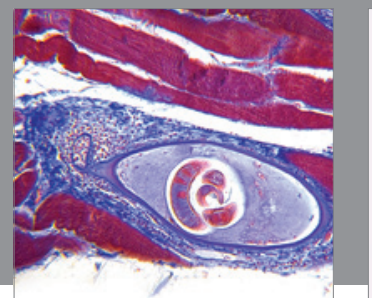

Gastroenterology

Research and Practice
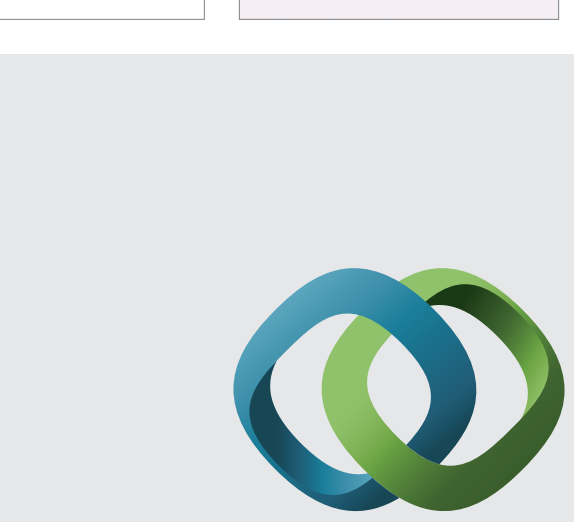

\section{Hindawi}

Submit your manuscripts at

http://www.hindawi.com
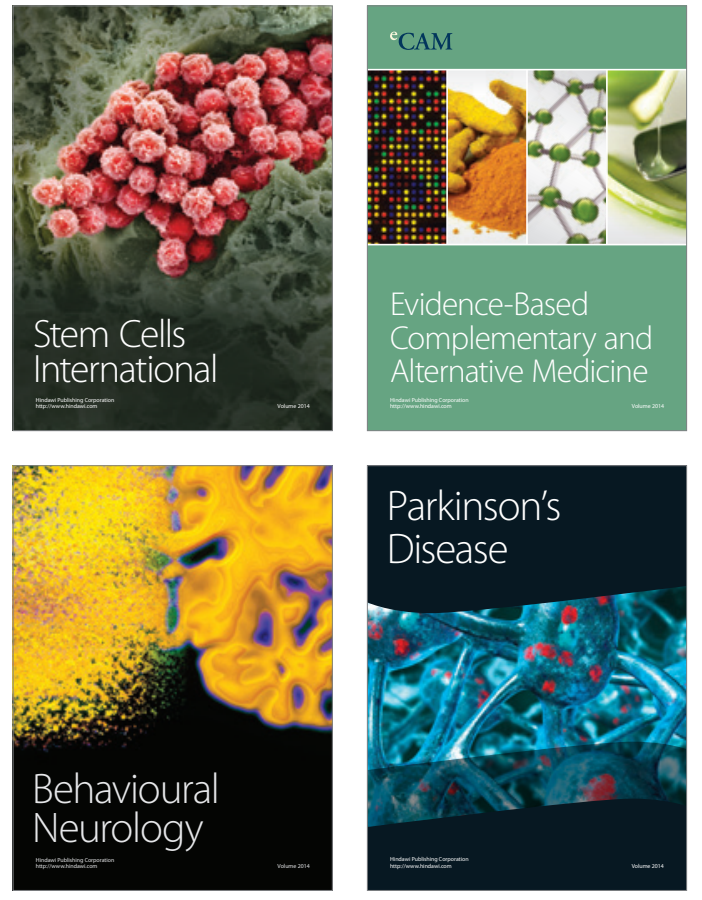
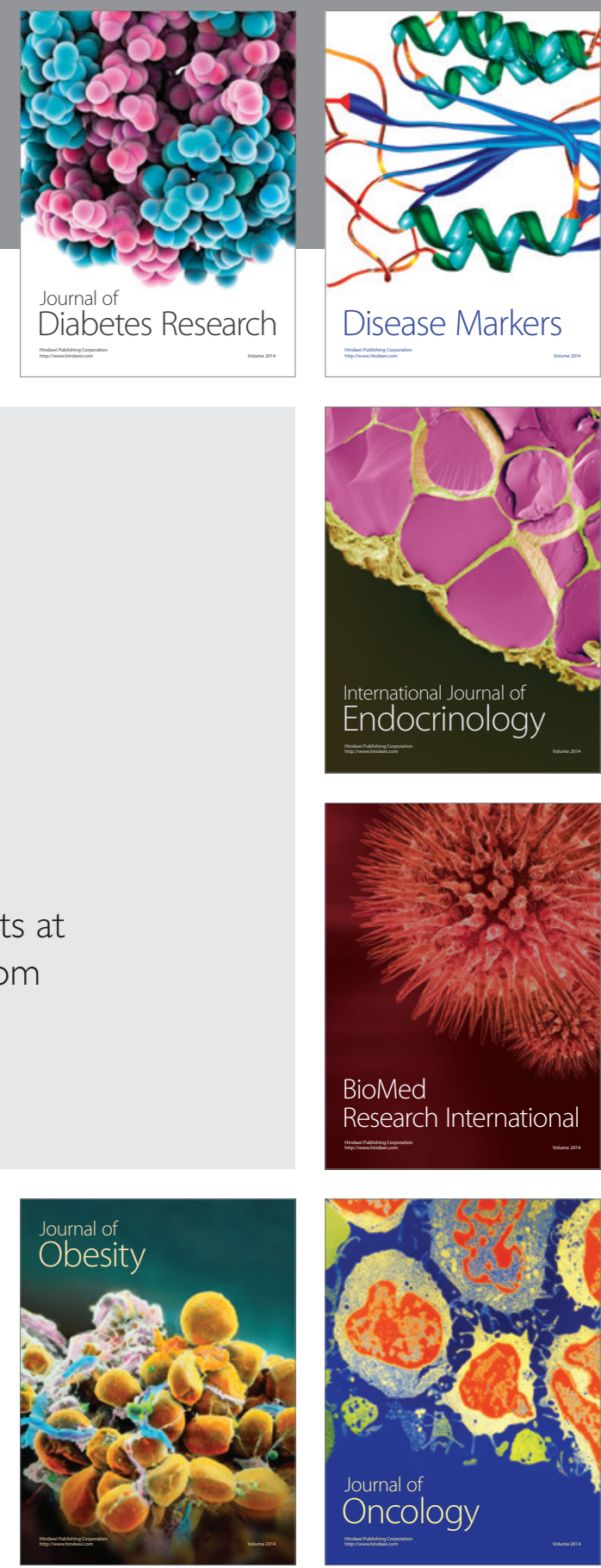

Disease Markers
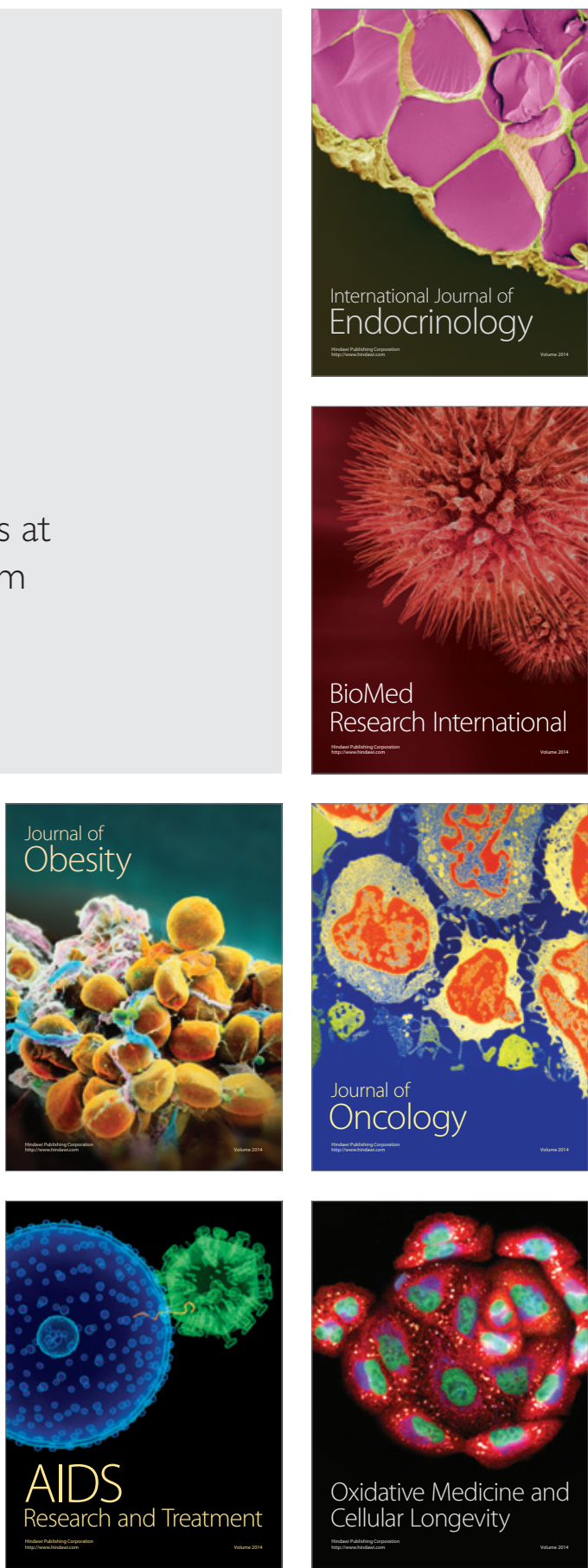